\title{
Adult hair follicle stem cells do not retain the older DNA strands in vivo during normal tissue homeostasis
}

\author{
Sanjeev K. Waghmare • Tudorita Tumbar
}

(C) Springer Science+Business Media Dordrecht 2013

\begin{abstract}
Tissue stem cells have been proposed to segregate the chromosomes asymmetrically (in a nonrandom manner), thereby retaining preferentially the older "immortal" DNA strands bearing the stemness characteristics into one daughter cell, whereas the newly synthesized strands are segregated to the other daughter cell that will commit to differentiation. Moreover, this non-random segregation would protect the stem cell genome from accumulating multiple mutations during repeated DNA replication. This long-standing hypothesis remains an active subject of study due to conflicting results for some systems and lack of consistency among different tissue stem cell populations. In this review, we will focus on work done in the hair follicle, which is one of the best-understood vertebrate tissue stem cell system to date. In cell culture analysis of paired cultured
\end{abstract}

Responsible Editors: Helder Maiato and Yves Barral

S. K. Waghmare $(\bowtie)$

Advanced Centre for Treatment, Research and Education

in Cancer (ACTREC), Tata Memorial Centre,

Navi Mumbai 410210, India

e-mail: swaghmare@actrec.gov.in

S. K. Waghmare

e-mail: sanjeev.waghmare@gmail.com

T. Tumbar $(\bowtie)$

Department of Molecular Biology and Genetics,

Cornell University,

258 Biotech,

Ithaca, NY 14853, USA

e-mail: tt252@cornell.edu keratinocytes derived from hair follicle, stem cells suggested a non-random segregation of chromosome with respect to the older DNA strand. In vivo, the hair follicle stem cells appear to self-renew and differentiate at different phases of their homeostatic cycle. The fate decisions occur in quiescence when some stem cells migrate out of their niche and commit to differentiation without self-renewal. The stem cells left behind in the niche selfrenew symmetrically and randomly segregate the chromosomes at each division, making more stem cells. This model seems to apply to at least a few other vertebrate tissue stem cells in vivo.

Keywords hair follicle stem cells · immortal strand hypothesis $\cdot$ non-random chromosome segregation . label retaining cells · histone H2B-GFP · pulse-chase

$\begin{array}{ll}\text { Abbreviations } \\ \text { BrdU } & \text { 5-Bromo-2'-deoxyuridine } \\ \text { LRC } & \text { Label retaining cell } \\ \text { H2B-GFP } & \text { Histone 2b-green fluorescent protein } \\ \text { GSC } & \text { Germ line stem cell } \\ \text { TPA } & \text { 12-O-Tetradecanoylphorbol-13-acetate } \\ \text { CldU } & \text { 5-Chloro-2-deoxy-uridine } \\ \text { IdU } & \text { 5-Iodo-2-deoxyuridine }\end{array}$

\section{Introduction}

Adult stem cells self-renew and differentiate throughout the life of an animal in order to maintain adult tissue homeostasis. At least some tissue stem cells, such as those of hair follicle and blood, divide 
infrequently, presumably to protect their genome from accumulating multiple mutations during repeated replication (Watt and Hogan 2000; Fuchs et al. 2004). Pulse-chase with labeled nucleotides such as 5-bromo$2^{\prime}$-deoxyuridine $(\mathrm{BrdU})$ or $\left[{ }^{3} \mathrm{H}\right]$ thymidine and more recently histone $\mathrm{H} 2 \mathrm{~B}-\mathrm{GFP}$ resulted in label retention (label retaining cells or LRCs) in a fraction of presumed tissue stem cells (Bickenbach 1981; Bickenbach and Grinnell 2004; Jensen et al. 2004; Sancho et al. 2004; Webb et al. 2004; Wilson et al. 2008; Foudi et al. 2009). In blood, the most quiescent stem cells have been clearly demonstrated to be the long-term most potent hematopoietic stem cells, as shown by H2B-GFP retention experiments followed by transplantations (Wilson et al. 2008; Foudi et al. 2009). In the hair follicle, the direct link between LRCs and stem cells has not been clearly established, but the most quiescent subset of cells from the bulge, the region of the hair where stem cells reside, have been deemed a potent "reserve" population that does not contribute to normal everyday tissue homeostasis (Hsu et al. 2011). Lineage tracing tracking the fate of these hair follicle LRCs is awaited to confirm this hypothesis. However, the LRCs are just the tip of the iceberg in this system, as all cells in the tissue zone containing the hair follicle stem cells divide infrequently overall and are thought to be stem cells (Waghmare et al. 2008; Zhang et al. 2009; Hsu et al. 2011). In the intestine, the Bmil-positive stem cells are the most infrequently dividing cells at the base of the crypt, and they rapidly regenerate intestinal crypts even when a more dispensable, proliferative Lgr5positive, stem cell population is absent (Tian et al. 2011; Buczacki et al. 2013).

Despite their unparalleled nature in potency and longevity within tissues, and despite intense studies to unravel their inherent molecular secrets, there is no cellular mechanism so far that only tissue stem cells possess. For this reason, the phenomenon of label retention has fascinated scientists for several decades, because it bears the promise for characterizing a unique cellular ability of stem cells. The label can be retained in theory by three possible mechanisms: (1) infrequent divisions, (2) no divisions, or (3) retaining the oldest, so-called "immortal DNA strand" by non-random chromosome segregation. The last model would imply that at mitosis, chromosomes are sorted according to the age of their DNA strands, such that the oldest strands are always segregated to the stem cell, while the newest strand would go to the progenitor cell daughter. As early as 1966 , uneven distribution of $\left[{ }^{3} \mathrm{H}\right]$ thymidine labeled sister chromatids was seen in cultured mouse embryonic fibroblast (Lark et al. 1966). The immortal strand hypothesis was first proposed by Cairns in 1975 and remained alive, but also controversial, until today (Cairns 1975, 2002; Potten et al. 2002; Cairns 2006; Lansdorp 2007; Rando 2007).

In the bacteria Escherichia coli, the theory of asymmetric chromosome segregation was first suggested many years ago (Lark et al. 1966) and was supported by additional studies (Helmstetter and Leonard 1987; Ogden et al. 1988). Recently, it was shown that sister chromosomes are destined to particular locations in the cells with respect to the cell poles versus cell body (Nielsen et al. 2006; Wang et al. 2006; White et al. 2008).

In the fly Drosophila melanogaster, the male germ stem cells (GSC) divide asymmetrically with respect to the hub cells, which play a niche role in this system (Kiger et al. 2001; Yamashita et al. 2003; Yamashita et al. 2005; Fuller and Spradling 2007; Losick et al. 2011). When GSCs divide, they produce one selfrenewed GSC that remains in contact with the hub and another daughter cell, the gonialblast, which would further differentiate (Yamashita et al. 2007). BrdU pulse-labeling showed that the chromosomes segregate randomly with respect to the age of the template DNA strand in GSC from Drosophila testis (Yadlapalli et al. 2011). In contrast, histones seem to show an asymmetric mode of segregation with the older histone remaining preferentially in the GSC (Tran et al. 2012)

In the yeast Saccharomyces cerevisiae, mitotic chromosome segregation error rate is as low as $10^{-5}$ per generation (Brown et al. 1991). Moreover, in S. cerevisiae, induced deletion of an entire chromosome leads to reduplication of the chromosome. This suggests that there exist mechanisms in the cell that control the euploidy of the chromosomes (Waghmare and Bruschi 2005). An early report suggested non-random segregation of mitotic chromosomes (Williamson and Fennell 1981 ), but later on this conclusion was challenged by further genetic tests (Neff and Burke 1991). Most recently, it was claimed that in fact all yeast chromosomes segregate randomly at mitosis (Keyes et al. 2008).

The flatworm Macrostomum lignano possesses pluripotent stem cells, referred to as neoblasts, which remain mitotically active during adulthood (Ladurner 
et al. 2000; Mouton et al. 2009). Neoblasts represents $6.5 \%$ of the 25,000 total cells in this worm (Bode et al. 2006) and have been recently shown to contain long-lived LRCs (Verdoodt et al. 2012). However, these LRCs seem to arise by quiescence and not by non-random chromosome segregation (Verdoodt et al. 2012).

In the mouse Mus musculus, several tissue stem cell systems have been examined. Intestinal stem cells were first proposed to segregate their chromosome asymmetrically (Potten et al. 1978), but this theory was challenged by more recent data (Escobar et al. 2011). Neural stem cell cultures showed that a subset of cells retain preferentially the BrdU signal, suggesting that there is asymmetric or non-random segregation of chromosome with respect to the template DNA strands (Karpowicz et al. 2005). This was also true of the mammary gland and muscle stem cells in vivo (Smith 2005; Shinin et al. 2006; Tajbakhsh et al. 2009) and of a few other cell culture systems (Merok et al. 2002; Armakolas and Klar 2006), including whisker follicle cells in culture (Huh et al. 2011). In contrast, the basal epidermis (Kuroki and Murakami 1989), blood (Kiel et al. 2007), and hair follicle (Sotiropoulou et al. 2008; Waghmare et al. 2008), in addition to the intestine (Li and Clevers 2010), showed random chromosome segregation in their stem cells in vivo during normal tissue homeostasis.

If retaining the older DNA strands is essential for preserving the stem cell genome, why do some stem cells evade this rule? The chromosome sorting model makes a first assumption that proved not to be true for all tissue stem cells: that each adult tissue stem cell division is asymmetric and generates two daughter cells always destined to a different fate (a stem cell and a transit-amplifying or short-lived progenitor cell). Co-incidentally, the same mouse tissue stem cells that do not seem to sort their chromosomes at division according to the age of their DNA template have also been shown by various means to divide symmetrically (Clayton et al. 2007; Zhang et al. 2009; Li and Clevers 2010).

In this review, we will focus on mouse hair follicle stem cell behavior in normal adult skin homeostasis with respect to the immortal strand hypothesis. These highly quiescent stem cells in vivo seem to self-renew symmetrically and randomly segregate their chromosomes at each division.

\section{A majority of hair follicle stem cells do not sort their chromosomes at division in vivo}

Skin is a self-regenerating tissue, which contains its own pool of specialized tissue stem cells. Mammalian skin consists of two tissue layers: epidermis and dermis. Epidermis is largely composed of keratinocytes, which make up the inter-follicular epidermis, the hair follicle, and the sebaceous gland, whereas dermis is composed largely of fibroblast. Stem cells in the epidermis not only ensure the maintenance of tissue homeostasis but also contribute to repair during injury. In mice, epidermis arises from a single layer of ectoderm, which begins to stratify at embryonic day E15.5 and also to invaginate downward to form the epidermal appendages. Signaling between the ectoderm and underlining mesoderm triggers the formation of a hair placode, which then matures and grows out of the skin after birth (Hardy 1992). Hair follicle morphogenesis is followed by the first adult hair cycle that comprises three stages namely: telogen (resting phase), anagen (growing phase), and catagen (regressing phase). The hair contains a temporary differentiated region called "bulb," composed of matrix cells that terminally differentiate into the inner hair follicle layers that includes the hair shaft. Hair follicle stem cells reside in the permanent bulge region, as first suggested by pulse-chase label retention studies using the ${ }^{3}[\mathrm{H}]$-thymidine and/or BrdU (Cotsarelis et al. 1990; Taylor et al. 2000; Oshima et al. 2001; Braun et al. 2003). The bulge stem cells give rise to hair follicle as shown by various methods including cell transplantation and lineage tracing in vivo (Taylor et al. 2000; Oshima et al. 2001; Morris et al. 2004; Jaks et al. 2008; Zhang et al. 2009; Scheitz et al. 2012). Originally, it was thought that hair follicles also make interfollicular epidermis and sebaceous gland, a structure situated on the top of the bulge known to produce the oil released in the hair canal (Bickenbach 1981; Lavker and Sun 1982; Taylor et al. 2000; Oshima et al. 2001; Braun et al. 2003; Blanpain et al. 2004). Subsequently, it was shown that these compartments have their own independent stem cells (Ito et al. 2005; Levy et al. 2005; Horsley et al. 2006). The multipotency of the hair follicle stem cells was demonstrated by performing various in vitro and in vivo single cell assays (Ghazizadeh and Taichman 2001; Blanpain et al. 2004; Claudinot et al. 2005; Zhang et al. 2009). 
LRCs obtained in hair follicles by injected $\left[{ }^{3} \mathrm{H}\right]-$ thymidine or BrdU for 3 days at postnatal days 3-5 followed by 7-8-weeks chase were deemed capable of forming colonies in culture (Morris and Potten 1994). This was suggested by identification of traces of label at the center of primary colonies obtained from cells freshly isolated from skin tissue and plated on fibroblast feeder cells. Also, bulge LRCs were capable of dividing in vivo upon stimulation with TPA or during wounding (Taylor et al. 2000; Braun et al. 2003). A pulse-chase method using double transgenic mice with repressible H2B-GFP via the tetracycline off system (Tumbar and Belmont 2001) endogenously marked the LRCs and did not require active proliferation of the cells during the pulse stage. In addition, these cells could be isolated live from the tissue. Despite early success in obtaining colonies from H2B-GFP LRCs in culture (Tumbar et al. 2004), these cells could not be propagated long-term or transplanted due to a toxic effect of the tet-VP16 component of the tetracycline system in combination with high H2B-GFP levels in cells extracted from skin tissue.

The H2B-GFP system allowed us to further develop a strategy to count in vivo the hair follicle stem cell division over time and provided the first quantitative proliferation history of tissue stem cells in an unperturbed tissue (Waghmare et al. 2008). Moreover, we used it to test the hypothesis of non-random chromosome segregation in hair follicle stem cells by double pulse-chase with BrdU and H2B-GFP (Fig. 1a). The results showed that the majority of the hair follicle bulge stem cells divide infrequently (one to five times) during the first hair cycle, with an average of $\sim 3$ divisions. Given an estimated ten hair cycles in a mouse lifetime, this suggests a mere of 30-50 total divisions for bulge cells throughout life in the absence of injury, an infrequent rate of division indeed for bulge cells overall. Given a low estimated rate of mutations of $10^{-6}$ per gene per replication, these few divisions are not likely to cause significant errors in the DNA.

Further attesting to the mode of chromosome segregation, the H2B-GFP and BrdU levels after chase paralleled each other (Fig. 2). Significantly, as the H2B-GFP signal was diluted by twofold at each division, the corresponding BrdU levels in those cells were equally halved (Waghmare et al. 2008). Bulge cells that divided more than three times, as shown by H2B-GFP levels, lost detectable BrdU label. Finally, we carefully analyzed the bulge cells with low H2BGFP levels due to multiple divisions, for the presence of rare bright BrdU-retaining cells due to preferential segregation of the older labeled DNA strands. We quantified the BrdU intensity and found that only 13 out of 2,199 (0.5\%) H2B-GFP dim bulge cells displayed small one to two BrdU-labeled foci. None of these cells showed bright BrdU signal indicative of preferential retention. These data were consistent with a model of random chromosome segregation with respect to the older DNA strands in hair follicle stem cells (Waghmare et al. 2008).

Subsequently, the Blanpain group also found that the majority of hair follicle stem cells show random chromosome segregation (Sotiropoulou et al. 2008). In this study, double-labeling pulse-chase experiments were performed by using two uridine analogues, namely 5chloro-2-deoxy-uridine (CldU) and 5-iodo-2-deoxyuridine (IdU). The administration of CldU was done in early postnatal life to label the bulge stem cells during hair development, when the bulge cells proliferate and can be completely labeled. Furthermore, mice were injected with IdU from PD23-PD25, the beginning of first adult hair cycle when stem cells proliferate once again. The random strand segregation model predicts that each chromosome has a $50 \%$ chance of being double-labeled after the first cell division, due to the semiconservative nature of DNA replication (Fig. 1b). Because mice have 40 chromosomes, the actual probability for a cell to be single labeled is $(1 / 2)^{40}$, which is negligible if the random segregation model applies. These double-positive cells would be progressively lost thereafter according to the number of divisions accomplished, which were counted using the pulse-chase H2B-GFP mouse system. The data were overwhelmingly in favor of the random segregation model, and ruled out the immortal strand hypothesis for a majority of the hair follicle stem cells in vivo (Sotiropoulou et al. 2008).

None of these two studies (Sotiropoulou et al. 2008; Waghmare et al. 2008) could rule out the presence within the bulge population of some very rare cells that segregate their chromosome asymmetrically with respect to the older strand, which may explain the long-term persistence of some LRCs within the skin (Morris and Potten 1999).

However, at a frequency lower than 1 in 2,000 for such hypothetical cells (Waghmare et al. 2008) and given an estimated 200 cells/2nd telogen bulge (Zhang et al. 2009; Zhang et al. 2010), these cells would not 
Fig. 1 Scheme of random and non-random segregation of chromosomes in BrdU and H2B-GFP double-labeled cells (a) and in CldU and IdU double-labeled cells (b)

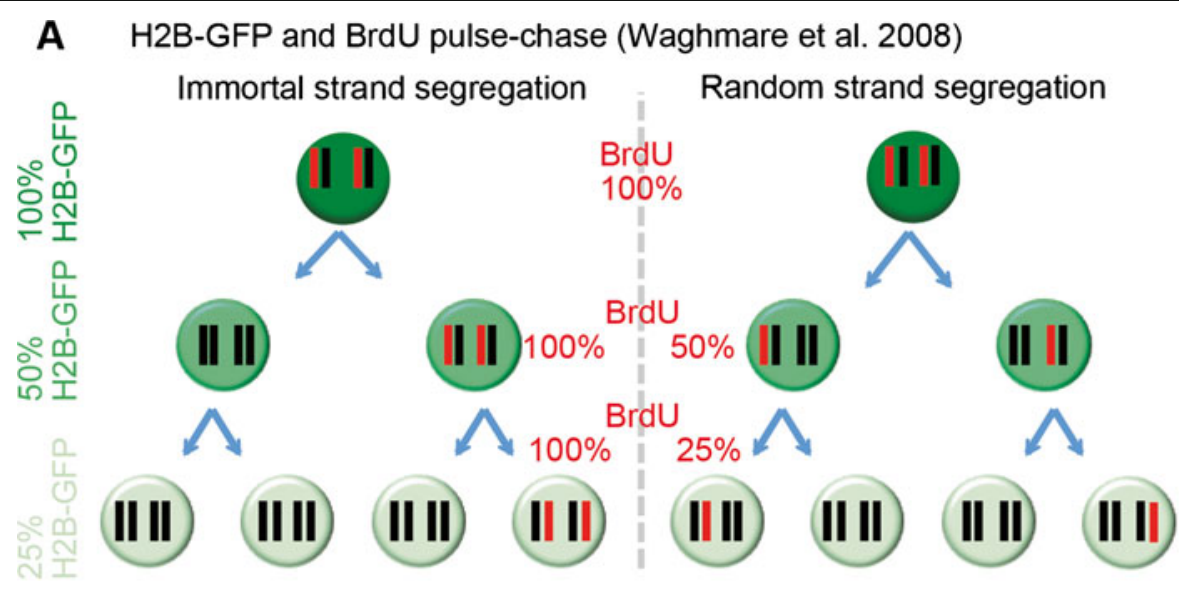

B H2B-GFP, CldU and IdU pulse-chase (Sotiropoulou et al. 2008)

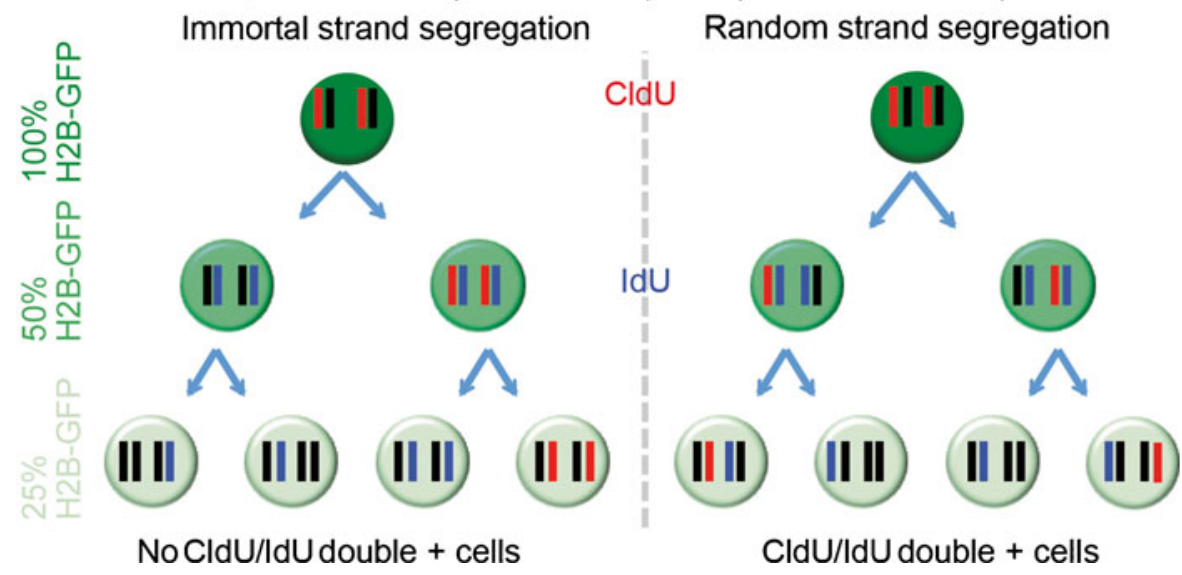

exist in every hair follicle, casting doubts over their potential role in tissue homeostasis. Another limitation is that, given $0.5 \%$ of bulge cells with more than five divisions showed rare BrdU-labeled foci (Waghmare et al. 2008), there is a possibility that one to two chromosomes in a couple of cells/bulge may present a biased mode of DNA strand segregation. This chromosome-specific bias was suggested for embryonic stem cell differentiation into endodermal cells (Armakolas and Klar 2006). The biological significance of such putative rare cells is not apparent given our current understanding of the hair follicle stem cell dynamics in the tissue.

In contrast to the results obtained in vivo, clonally expanded whisker hair follicle stem cells in vitro showed non-random chromosome segregation in a significant fraction of the cell pairs analyzed (Huh et al. 2011). Moreover, Lgr5, which is expressed by hair follicle stem cells (Jaks et al. 2008), showed nuclear expression preferentially in the daughter cell that also retained cyclin A and non-randomly co-segregated chromosomes (Huh et al. 2011). At the first glance, this result may suggest that hair follicle stem cells behave differently in vivo and in vitro. Huh et al. suggest that in vivo assays may lack the required sensitivity necessary to detect rare asymmetric divisions, although an explanation for how the quantitative methods used by Sotiropoulou et al. (2008) and Waghmare et al. 2008) were misinterpreted is not apparent. If double nucleotide labeling on transgenes of H2B-GFP induces toxicity as suggested (Huh et al. 2011), thereby perturbing the system, it appears that the non-random chromosome segregation was not required for normal hair cycle and long-term survival of stem cells in these mice. In addition, Huh et al. suggest that the predominant symmetric renewal in vivo, which was in fact proposed in earlier work (Zhang et al. 2009), may explain the discrepancy in results obtained in the different conditions. The assumption that hair follicle stem cells self-renew asymmetrically 


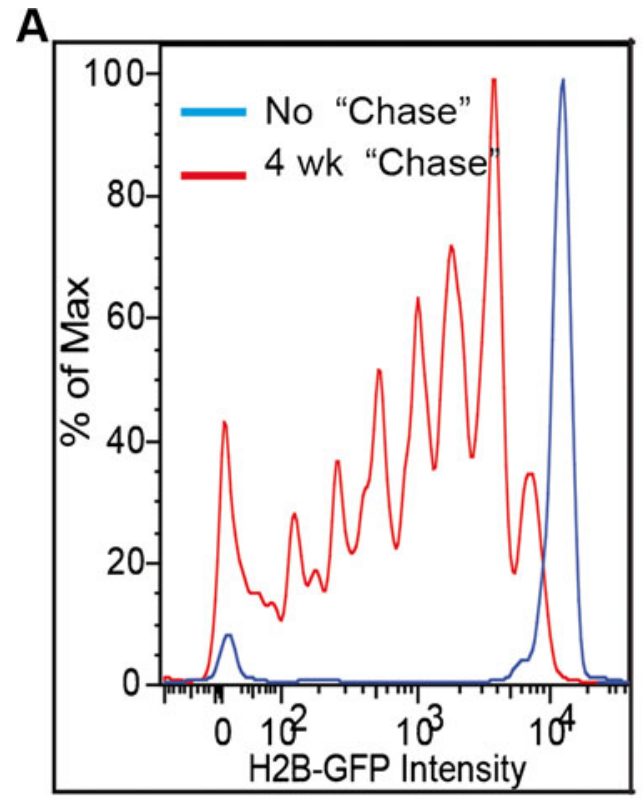

C

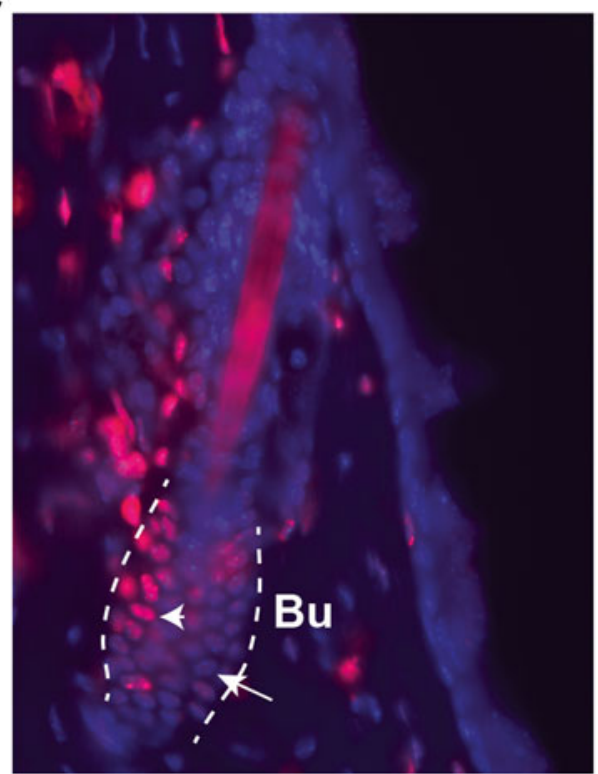

Fig. 2 Long-term BrdU LRCs in hair follicle dilute the label with division showing random chromosome segregation (adapted from Waghmare et al. 2008). a Fluorescence activated cell sorting of hair follicle stem cells as marked by $\mathrm{CD} 34$, and $\alpha$ 6-integrin shows histogram as a function of H2B-GFP fluorescence. After 4 weeks of doxycycline chase to shut down H2B-GFP transcription, peaks of H2B-GFP

in culture (Huh et al. 2011), and therefore could not be expanded symmetrically, contradicts earlier data in which single whisker bulge cells have been propagated in culture to numbers that could reconstitute many hair
B

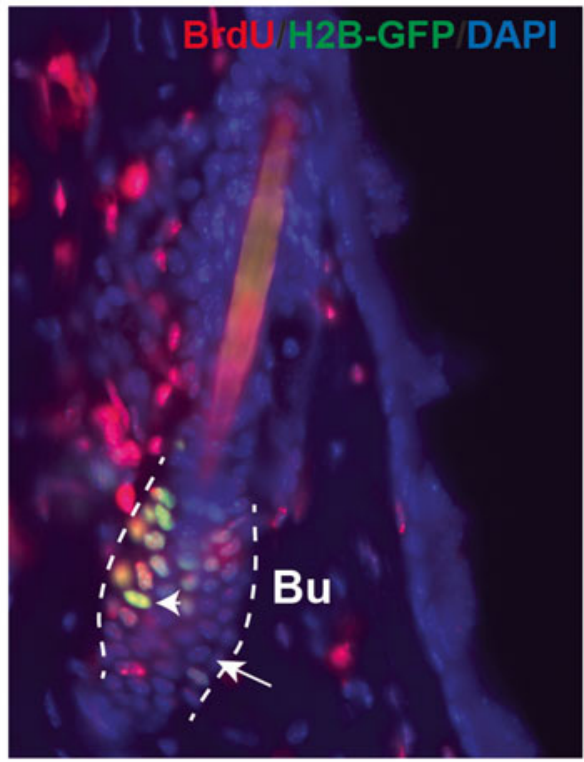

D

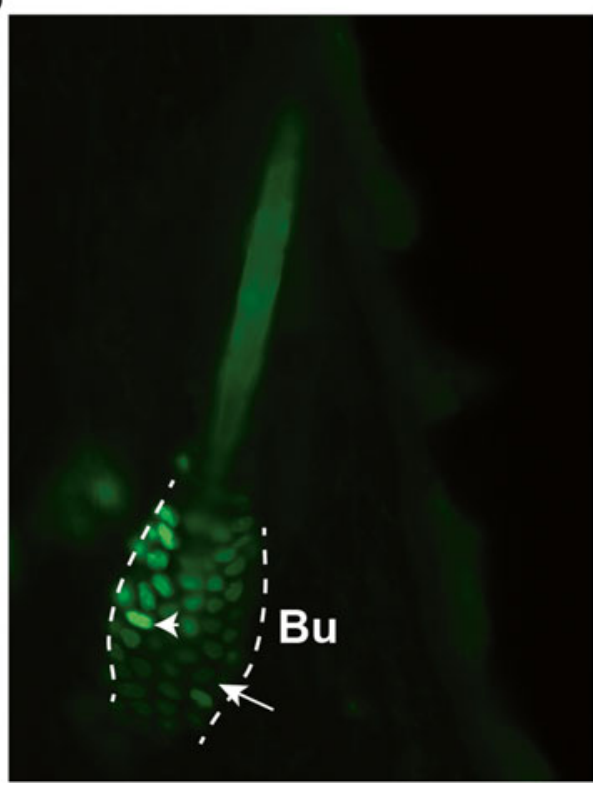

fluorescence are separated by twofold intensity signal, indicative of one division. b Skin section from mice injected with BrdU in hair morphogenesis and chased into adulthood. An overlapping 4-week doxycyline chase showed that BrdU and H2B-GFP intensity overlap (arrow shows a dim cell and arrowhead shows a bright cell). Individual colors of the same image are shown in $\mathbf{c}$ and $\mathbf{d}$

follicle over two rounds of transplantation and over 1 year of hair growth (Claudinot et al. 2005). In addition, most keratinocytes in culture are likely non-stem cells but rather rapidly dividing transit- 
amplifying cells generated by rare stem cells, as suggested by detailed early clonal analysis (Barrandon and Green 1988). Moreover, Lgr5, although expressed in some (but not all) HFSCs, is also expressed by more committed progenitor cells as well (Hsu et al. 2011). In fact, in the study by Huh et al., Lgr5 seems to segregate in the cell that also acquires cyclin A, which may be the rapidly dividing transit-amplifying daughter cell rather than the stem cell, while the non-cyclin A, non-Lgr5 daughter cell has withdrawn from the cell cycle and is terminally differentiated. Zhang et al. suggested that divisions in the bulge (stem cell compartment) are parallel (symmetric) with respect to the basement membrane, while in the matrix transit-amplifying cells they are perpendicular (asymmetric) to the basement membrane (Zhang et al. 2010). Similar with the scenario suggested in hair follicle, in a tour-de-force study, Williams et al. showed that asymmetric division in the epidermis is likely associated with differentiation of transit-amplifying cells, rather than with the selfrenewal of stem cells (Williams et al. 2011). If the non-random segregation of chromosome goes along with other aspects of asymmetric cell division, it would in fact be interesting to examine the patterns of chromosome segregation in the hair matrix rather than in the hair bulge. The matrix, as the transitamplifying hair follicle cell population, may more closely resemble the scenario encountered in cell culture. However, if truly the transit-amplifying cells would undergo non-random chromosome segregation, the purpose of retaining a more intact copy of the genome in such a short-lived cell is not immediately obvious, unless we consider aspects beyond genome preservation. Recently, preferential retention of the older histone in the germ line stem cell daughter, along with presumably all its epigenetic modification, may be a potential (but speculative) mechanism of cell fate preservation (Tran et al. 2012). Given DNA methylation, like histone modification, is also implicated in regulating cell differentiation and cellular identity, non-random chromosome segregation would in that case have potential implications beyond genome preservation of stem cells, such as epigenetic fate retention in an asymmetrically dividing transit-amplifying cell. Aside from these speculations, it remains in fact unclear why there is discrepancy with respect to the immortal strand hypothesis in cell culture and in vivo in the hair follicle system.

\section{Conclusions and future perspectives}

In conclusion, characterization of stem cell dynamics in the bulge compartment of the hair follicle in vivo in the intact tissue showed random chromosome segregation with respect to the older DNA strands in normal homeostasis. In addition, these stem cells seem to selfrenew symmetrically in vivo, generating at each division two identical stem cells that remain in the niche (bulge) until further mobilization by tissue migratory signals that stimulate them to leave the niche and promote their differentiation. Recent studies testing the immortal strand hypothesis in hair follicle in vivo involved different quantitative complementary methods from two research groups, which independently reached similar conclusions, strengthening the validity of the data. In addition, the analysis was done in unperturbed skin, in the absence of injury and drug stimulation, which could affect the normal behavior of tissue stem cells. These data contrasted with results obtain in cultured cells in vitro, which might reflect differences in stem cell behavior in different growth condition, hidden experimental and technical difficulties that may influence the data interpretation, or a speculative possibility that cell culture data may in fact be more reflective of transit-amplifying cell behavior, which has not been tested in vivo.

However, based on the data in hand, it seems clear that in vivo the hair follicle stem cells, and other tissue stem cells as well, behave more ordinary in their native environment than initially imagined by some of us. The lack of immortal strands left us bare-handed in identifying unique cellular characteristics in these tissue stem cells. Some genes are preferentially expressed in hair follicle stem cells, and of these, some specific transcription factors such as Tbx1 and Runx1, to name a few, drive the hair follicle stem cell selfrenewal and proliferation (Osorio et al. 2008; Hoi et al. 2010; Osorio et al. 2011; Chen et al. 2012; Lee et al. 2013), and Dlx3 drives their differentiation (Hwang et al. 2008). Undoubtedly, more transcription factors will surface that will likely interface with chromatinmodifying enzymes, microRNAs, and long noncoding RNAs to control the tissue stem cell behavior. Regulatory networks as described in embryonic stem cells, with nodes of interaction controlled by master regulators, most likely will be drawn for hair follicle and other tissue stem cells. As genomic approaches become more accessible for small sample sizes 
afforded by tissue stem cells, comparison with the cancer cells is likely to reveal significant overlap, since at least some cancer stem cells appear to originate in tissue stem cells (Sell 2004).

The interaction of hair follicle stem cells with some of the surrounding compartments in the skin is a new and exciting area of investigation (Goldstein and Horsley 2012; Chang et al. 2013). Perhaps not surprisingly, these compartments communicate via various signals and function in concert to maintain skin homeostasis. While much is left to know about these interactions, the field is becoming sufficiently mature to begin to tackle in more detail the molecular connection with specific disease. This will be facilitated by our ability to model human disease in the dish using induced pluripotent stem cells (Bellin et al. 2012). Generating hair follicle in organotypic culture remains a big challenge of the field. Stem cells did not reveal all of their secrets, however, and a large fraction of genes specifically expressed by stem cells remain uncharacterized. What will be the next "immortal" hypothesis that will keep the tissue stem cell field going for 40 years is hard to imagine in this era of rapid progress and quick concept turnover. The field is becoming less mysterious, perhaps losing some of its original aura, but the pace of the progress is exhilarating, making it a privilege as a researcher to add a small part to stem cell biology.

Acknowledgments This work was supported in part by funding from the National Institutes of Health Grant R01AR053201 (to T.T.) and by ACTREC start up fund (to SKW).

\section{References}

Armakolas A, Klar AJ (2006) Cell type regulates selective segregation of mouse chromosome 7 DNA strands in mitosis. Science 311:1146-1149

Barrandon Y, Li V, Green H (1988) New techniques for the grafting of cultured human epidermal cells onto athymic animals. J Investig Dermatol 91:315-318

Bellin M, Marchetto MC, Gage FH, Mummery CL (2012) Induced pluripotent stem cells: the new patient? Nat Rev Mol Cell Biol 13:713-726

Bickenbach JR (1981) Identification and behavior of labelretaining cells in oral mucosa and skin. J Dent Res $60 \mathrm{Spec}$ No C:1611-1620.

Bickenbach JR, Grinnell KL (2004) Epidermal stem cells: interactions in developmental environments. Differentiation 72:371-380

Blanpain C, Lowry WE, Geoghegan A, Polak L, Fuchs E (2004) Self-renewal, multipotency, and the existence of two cell populations within an epithelial stem cell niche. Cell 118: 635-648

Bode A, Salvenmoser W, Nimeth K, Mahlknecht M, Adamski Z, Rieger RM, Peter R, Ladurner P (2006) Immunogoldlabeled S-phase neoblasts, total neoblast number, their distribution, and evidence for arrested neoblasts in Macrostomum lignano (Platyhelminthes, Rhabditophora). Cell Tissue Res 325:577-587

Braun KM, Niemann C, Jensen UB, Sundberg JP, Silva-Vargas V, Watt FM (2003) Manipulation of stem cell proliferation and lineage commitment: visualisation of label-retaining cells in wholemounts of mouse epidermis. Development 130:5241-5255

Brown M, Garvik B, Hartwell L, Kadyk L, Seeley T, Weinert T (1991) Fidelity of mitotic chromosome transmission. Cold Spring Harb Symp Quant Biol 56:359-365

Buczacki SJ, Zecchini HI, Nicholson AM, Russell R, Vermeulen L, Kemp R, Winton DJ (2013) Intestinal label-retaining cells are secretory precursors expressing Lgr5. Nature 495:65-69

Cairns J (1975) Mutation selection and the natural history of cancer. Nature 255:197-200

Cairns J (2002) Somatic stem cells and the kinetics of mutagenesis and carcinogenesis. Proc Natl Acad Sci U S A 99:10567-10570

Cairns J (2006) Cancer and the immortal strand hypothesis. Genetics 174:1069-1072

Chang CY, Pasolli HA, Giannopoulou EG, Guasch G, Gronostajski RM, Elemento O, Fuchs E (2013) NFIB is a governor of epithelial-melanocyte stem cell behaviour in a shared niche. Nature 495:98-102

Chen T, Heller E, Beronja S, Oshimori N, Stokes N, Fuchs E (2012) An RNA interference screen uncovers a new molecule in stem cell self-renewal and long-term regeneration. Nature 485:104-108

Claudinot S, Nicolas M, Oshima H, Rochat A, Barrandon Y (2005) Long-term renewal of hair follicles from clonogenic multipotent stem cells. Proc Natl Acad Sci U S A 102:14677-14682

Clayton E, Doupe DP, Klein AM, Winton DJ, Simons BD, Jones PH (2007) A single type of progenitor cell maintains normal epidermis. Nature 446:185-189

Cotsarelis G, Sun TT, Lavker RM (1990) Label-retaining cells reside in the bulge area of pilosebaceous unit: implications for follicular stem cells, hair cycle, and skin carcinogenesis. Cell 61:1329-1337

Escobar M, Nicolas P, Sangar F, Laurent-Chabalier S, Clair P, Joubert D, Jay P, Legraverend C (2011) Intestinal epithelial stem cells do not protect their genome by asymmetric chromosome segregation. Nat Commun 2:258

Foudi A, Hochedlinger K, Van Buren D, Schindler JW, Jaenisch R, Carey V, Hock H (2009) Analysis of histone 2B-GFP retention reveals slowly cycling hematopoietic stem cells. Nat Biotechnol 27:84-90

Fuchs E, Tumbar T, Guasch G (2004) Socializing with the neighbors: stem cells and their niche. Cell 116:769-778

Fuller MT, Spradling AC (2007) Male and female Drosophila germline stem cells: two versions of immortality. Science 316:402-404

Ghazizadeh S, Taichman LB (2001) Multiple classes of stem cells in cutaneous epithelium: a lineage analysis of adult mouse skin. EMBO J 20:1215-1222 
Goldstein J, Horsley V (2012) Home sweet home: skin stem cell niches. Cellular and molecular life sciences: CMLS 69: 2573-2582

Hardy MH (1992) The secret life of the hair follicle. Trends Genet 8:55-61

Helmstetter CE, Leonard AC (1987) Mechanism for chromosome and minichromosome segregation in Escherichia coli. J Mol Biol 197:195-204

Hoi CS, Lee SE, Lu SY, McDermitt DJ, Osorio KM, Piskun CM, Peters RM, Paus R, Tumbar T (2010) Runx1 directly promotes proliferation of hair follicle stem cells and epithelial tumor formation in mouse skin. Mol Cell Biol 30:2518-2536

Horsley V, O'Carroll D, Tooze R, Ohinata Y, Saitou M, Obukhanych T, Nussenzweig M, Tarakhovsky A, Fuchs E (2006) Blimp1 defines a progenitor population that governs cellular input to the sebaceous gland. Cell 126:597-609

Hsu YC, Pasolli HA, Fuchs E (2011) Dynamics between stem cells, niche, and progeny in the hair follicle. Cell 144:92-105

Huh YH, King J, Cohen J, Sherley JL (2011) SACK-expanded hair follicle stem cells display asymmetric nuclear Lgr5 expression with non-random sister chromatid segregation. Sci Rep 1:176

Hwang J, Mehrani T, Millar SE, Morasso MI (2008) Dlx3 is a crucial regulator of hair follicle differentiation and cycling. Development 135:3149-3159

Ito M, Liu Y, Yang Z, Nguyen J, Liang F, Morris RJ, Cotsarelis G (2005) Stem cells in the hair follicle bulge contribute to wound repair but not to homeostasis of the epidermis. Nat Med 11:1351-1354

Jaks V, Barker N, Kasper M, van Es JH, Snippert HJ, Clevers H, Toftgard R (2008) Lgr5 marks cycling, yet long-lived, hair follicle stem cells. Nat Genet 40:1291-1299

Jensen CH, Jauho EI, Santoni-Rugiu E, Holmskov U, Teisner B, Tygstrup N, Bisgaard HC (2004) Transit-amplifying ductular (oval) cells and their hepatocytic progeny are characterized by a novel and distinctive expression of delta-like protein/preadipocyte factor $1 /$ fetal antigen 1 . Am J Pathol 164:1347-1359

Karpowicz P, Morshead C, Kam A, Jervis E, Ramunas J, Cheng V, van der Kooy D (2005) Support for the immortal strand hypothesis: neural stem cells partition DNA asymmetrically in vitro. J Cell Biol 170:721-732

Keyes BE, Yellman CM, Burke DJ (2008) Differential regulation of anaphase promoting complex/cyclosome substrates by the spindle assembly checkpoint in Saccharomyces cerevisiae. Genetics 178:589-591

Kiel MJ, He S, Ashkenazi R, Gentry SN, Teta M, Kushner JA, Jackson TL, Morrison SJ (2007) Haematopoietic stem cells do not asymmetrically segregate chromosomes or retain BrdU. Nature 449:238-242

Kiger AA, Jones DL, Schulz C, Rogers MB, Fuller MT (2001) Stem cell self-renewal specified by JAK-STAT activation in response to a support cell cue. Science 294:2542-2545

Kuroki T, Murakami Y (1989) Random segregation of DNA strands in epidermal basal cells. Jpn J Cancer Res 80:637642

Ladurner P, Rieger R, Baguna J (2000) Spatial distribution and differentiation potential of stem cells in hatchlings and adults in the marine Platyhelminth macrostomum sp.: a bromodeoxyuridine analysis. Dev Biol 226:231241

Lansdorp PM (2007) Immortal strands? Give me a break. Cell 129:1244-1247

Lark KG, Consigli RA, Minocha HC (1966) Segregation of sister chromatids in mammalian cells. Science 154:12021205

Lavker RM, Sun TT (1982) Heterogeneity in epidermal basal keratinocytes: morphological and functional correlations. Science 215:1239-1241

Lee J, Hoi C, Lilja K, White B, Lee S, Shalloway D, Tumbar T (2013) Runx 1 and p21 synergistically limit the extent of hair follicle stem cell quiescence in vivo. Proceedings of the National Academy of Science 110(12):4634-4639

Levy V, Lindon C, Harfe BD, Morgan BA (2005) Distinct stem cell populations regenerate the follicle and interfollicular epidermis. Dev Cell 9:855-861

Li L, Clevers H (2010) Coexistence of quiescent and active adult stem cells in mammals. Science 327:542-545

Losick VP, Morris LX, Fox DT, Spradling A (2011) Drosophila stem cell niches: a decade of discovery suggests a unified view of stem cell regulation. Dev Cell 21:159-171

Merok JR, Lansita JA, Tunstead JR, Sherley JL (2002) Cosegregation of chromosomes containing immortal DNA strands in cells that cycle with asymmetric stem cell kinetics. Cancer Res 62:6791-6795

Morris RJ, Liu Y, Marles L, Yang Z, Trempus C, Li S, Lin JS, Sawicki JA, Cotsarelis G (2004) Capturing and profiling adult hair follicle stem cells. Nat Biotechnol 22:411-417

Morris RJ, Potten CS (1994) Slowly cycling (label-retaining) epidermal cells behave like clonogenic stem cells in vitro. Cell Prolif 27:279-289

Morris RJ, Potten CS (1999) Highly persistent labelretaining cells in the hair follicles of mice and their fate following induction of anagen. J Invest Dermatol 112:470-475

Mouton S, Willems M, Braeckman BP, Egger B, Ladurner P, Scharer L, Borgonie G (2009) The free-living flatworm Macrostomum lignano: a new model organism for ageing research. Exp Gerontol 44:243-249

Neff MW, Burke DJ (1991) Random segregation of chromatids at mitosis in Saccharomyces cerevisiae. Genetics 127:463473

Nielsen HJ, Ottesen JR, Youngren B, Austin SJ, Hansen FG (2006) The Escherichia coli chromosome is organized with the left and right chromosome arms in separate cell halves. Mol Microbiol 62:331-338

Ogden GB, Pratt MJ, Schaechter M (1988) The replicative origin of the $E$. coli chromosome binds to cell membranes only when hemimethylated. Cell 54:127-135

Oshima H, Rochat A, Kedzia C, Kobayashi K, Barrandon Y (2001) Morphogenesis and renewal of hair follicles from adult multipotent stem cells. Cell 104:233-245

Osorio KM, Lee SE, McDermitt DJ, Waghmare SK, Zhang YV, Woo HN, Tumbar T (2008) Runx1 modulates developmental, but not injury-driven, hair follicle stem cell activation. Development 135:1059-1068

Osorio KM, Lilja KC, Tumbar T (2011) Runx1 modulates adult hair follicle stem cell emergence and maintenance from distinct embryonic skin compartments. J Cell Biol 193: 235-250 
Potten CS, Hume WJ, Reid P, Cairns J (1978) The segregation of DNA in epithelial stem cells. Cell 15:899-906

Potten CS, Owen G, Booth D (2002) Intestinal stem cells protect their genome by selective segregation of template DNA strands. J Cell Sci 115:2381-2388

Rando TA (2007) The immortal strand hypothesis: segregation and reconstruction. Cell 129:1239-1243

Sancho E, Batlle E, Clevers H (2004) Signaling pathways in intestinal development and cancer. Annu Rev Cell Dev Biol 20:695-723

Scheitz CJ, Lee TS, McDermitt DJ, Tumbar T (2012) Defining a tissue stem cell-driven Runx1/Stat3 signalling axis in epithelial cancer. EMBO J 31:4124-4139

Sell S (2004) Stem cell origin of cancer and differentiation therapy. Crit Rev Oncol Hematol 51:1-28

Shinin V, Gayraud-Morel B, Gomes D, Tajbakhsh S (2006) Asymmetric division and cosegregation of template DNA strands in adult muscle satellite cells. Nat Cell Biol 8:677-687

Smith GH (2005) Label-retaining epithelial cells in mouse mammary gland divide asymmetrically and retain their template DNA strands. Development 132:681-687

Sotiropoulou PA, Candi A, Blanpain C (2008) The majority of multipotent epidermal stem cells do not protect their genome by asymmetrical chromosome segregation. Stem Cells 26:2964-2973

Tajbakhsh S, Rocheteau P, Le Roux I (2009) Asymmetric cell divisions and asymmetric cell fates. Annu Rev Cell Dev Biol 25:671-699

Taylor G, Lehrer MS, Jensen PJ, Sun TT, Lavker RM (2000) Involvement of follicular stem cells in forming not only the follicle but also the epidermis. Cell 102:451-461

Tian H, Biehs B, Warming S, Leong KG, Rangell L, Klein OD, de Sauvage FJ (2011) A reserve stem cell population in small intestine renders Lgr5-positive cells dispensable. Nature 478:255-259

Tran V, Lim C, Xie J, Chen X (2012) Asymmetric division of Drosophila male germline stem cell shows asymmetric histone distribution. Science 338:679-682

Tumbar T, Belmont AS (2001) Interphase movements of a DNA chromosome region modulated by VP16 transcriptional activator. Nat Cell Biol 3:134-139

Tumbar T, Guasch G, Greco V, Blanpain C, Lowry WE, Rendl M, Fuchs E (2004) Defining the epithelial stem cell niche in skin. Science 303:359-363

Verdoodt F, Willems M, Mouton S, De Mulder K, Bert W, Houthoofd W, Smith J 3rd, Ladurner P (2012) Stem cells propagate their DNA by random segregation in the flatworm Macrostomum lignano. PLoS One 7:e30227

Waghmare SK, Bansal R, Lee J, Zhang YV, McDermitt DJ, Tumbar T (2008) Quantitative proliferation dynamics and random chromosome segregation of hair follicle stem cells. EMBO J 27:1309-1320

Waghmare SK, Bruschi CV (2005) Differential chromosome control of ploidy in the yeast Saccharomyces cerevisiae. Yeast 22:625-639

Wang X, Liu X, Possoz C, Sherratt DJ (2006) The two Escherichia coli chromosome arms locate to separate cell halves. Genes Dev 20:1727-1731

Watt FM, Hogan BL (2000) Out of Eden: stem cells and their niches. Science. 287:1427-1430

Webb A, Li A, Kaur P (2004) Location and phenotype of human adult keratinocyte stem cells of the skin. Differentiation 72:387-395

White MA, Eykelenboom JK, Lopez-Vernaza MA, Wilson E, Leach DR (2008) Non-random segregation of sister chromosomes in Escherichia coli. Nature 455:12481250

Williams SE, Beronja S, Pasolli HA, Fuchs E (2011) Asymmetric cell divisions promote Notch-dependent epidermal differentiation. Nature 470:353-358

Williamson DH, Fennell DJ (1981 ) Non-random assortment of sister chromatids in yeast mitosis. In: Von Wettstein D, et al. (eds) Molecular Genetics in Yeast, Alfred Benzon Symposium, Copenhagen, Munksgaard 16:89-102

Wilson A, Laurenti E, Oser G, van der Wath RC, BlancoBose W, Jaworski M, Offner S, Dunant CF, Eshkind L, Bockamp E, Lio P, Macdonald HR, Trumpp A (2008) Hematopoietic stem cells reversibly switch from dormancy to self-renewal during homeostasis and repair. Cell 135:1118-1129

Yadlapalli S, Cheng J, Yamashita YM (2011) Drosophila male germline stem cells do not asymmetrically segregate chromosome strands. J Cell Sci 124:933-939

Yamashita YM, Fuller MT, Jones DL (2005) Signaling in stem cell niches: lessons from the Drosophila germline. J Cell Sci 118:665-672

Yamashita YM, Jones DL, Fuller MT (2003) Orientation of asymmetric stem cell division by the APC tumor suppressor and centrosome. Science 301:1547-1550

Yamashita YM, Mahowald AP, Perlin JR, Fuller MT (2007) Asymmetric inheritance of mother versus daughter centrosome in stem cell division. Science 315:518-521

Zhang YV, Cheong J, Ciapurin N, McDermitt DJ, Tumbar T (2009) Distinct self-renewal and differentiation phases in the niche of infrequently dividing hair follicle stem cells. Cell Stem Cell 5:267-278

Zhang YV, White BS, Shalloway DI, Tumbar T (2010) Stem cell dynamics in mouse hair follicles: a story from cell division counting and single cell lineage tracing. Cell Cycle 9:1504-1510 